\title{
NOTES
}

\section{Synonomy of the Yeast Genera Saccharomyces Meyen ex Hansen and Pachytichospora van der Walt}

\author{
ANN VAUGHAN-MARTINI* AND PAOLA POLLACCI \\ Industrial Yeasts Collection, Sez. Microbiologia Applicata, Dipartimento di \\ Biologia Vegetale, Università degli Studi, Perugia, Italy
}

\begin{abstract}
The type strains and other strains of the phenotypically similar taxa Saccharomyces castellii Capriotti, Saccharomyces dairensis Naganishi, and Pachytichospora transvaalensis van der Walt were studied by comparing the ascospore morphologies of these organisms by examining ultrathin sections by transmission electron microscopy. The results of this study and another investigation of DNA base sequence homology demonstrated that the monotypic genus Pachytichospora van der Walt is invalid. We propose that the species Saccharomyces transvaalensis van der Walt should be reinstated.
\end{abstract}

The genus Pachytichospora was created by van der Walt (15) for the species Saccharomyces transvaalensis on the basis of apparent morphological differences between the ascospores of the type strain of this species (16) and those of the type strain of the phenotypically similar taxon Saccharomyces dairensis Naganishi (12). Since a recent study of DNA nucleotide base sequences (16a) revealed that the levels of relatedness for the type strains of these species, as well as the type strain of Saccharomyces castellii, are variable, it was decided to examine ultrathin sections of sporulating cultures of the three species by transmission electron microscopy. Cultures were obtained from the Yeast Division of the Centraalbureau voor Schimmelcultures Collection, Delft, The Netherlands. When possible, the type strain and at least one other strain of each species were studied.

Cells from a sporulating culture on McClary's acetate agar (10) were prepared for analysis of ultrathin sections by transmission electron microscopy. The cells were first fixed for $1 \mathrm{~h}$ at $4^{\circ} \mathrm{C}$ in $3 \%$ ( $\mathrm{vol} / \mathrm{vol}$ ) glutaraldehyde in $0.1 \mathrm{M}$ cacodylate buffer ( $\mathrm{pH} \mathrm{7.0)}$ and then postfixed for $2 \mathrm{~h}$ in $1 \%$ osmium tetroxide in the same buffer. After dehydration with ethanol, the cells were infiltrated with propylene oxide. Ultrathin sections of the material embedded in an Epon-Araldite resin were stained by treating them with a saturated solution of uranyl acetate in $50 \%$ ethanol. Preparations were examined with a Philips model TEM 400 microscope.

In most cases very low percentages of sporulation were observed after at least 7 to 14 days of incubation at temperatures ranging from 4 to $25^{\circ} \mathrm{C}$. One-spore asci predominated, while asci containing two spores were found less frequently. Fourspore asci were never observed. Light microscopic observations of Pachytichospora transvaalensis strains revealed that, as noted previously by other authors $(3,15,16)$, relatively large, highly refringent ascospores that were apparently quite different from the ascospores produced by strains of the other two species were present.

In this study the transmission electron microscope observations of van der Walt and Liebenberg (16) were partially con-

\footnotetext{
* Corresponding author. Mailing address: Sez. Microbiologia Applicata, Dipartimento di Biologia Vegetale, Borgo XX Giugno, 74, Perugia, Italy 06121. Phone: 3975585 6479. Fax: 39755856470.
}

firmed, and thin-walled ascospores were present in the Saccharomyces dairensis type strain preparation (Fig. 1a). However, since thick-walled ascospores were also present in the same preparation (Fig. 1b), wall thickness could be a function of relative ascospore maturity. Kreger-van Rij (5) observed that the walls of Saccharomyces cerevisiae ascospores undergo a series of modifications during maturation and germination. Black and Gorman (2) also found that the development of spores in Hansenula wingei (now classified as Pichia canadensis [8]) "proceeds with separation of the two tracks of investing membrane and deposition of mucopolysaccharide in the intercisternal space." All of the other strains examined ( $P$. transvaalensis DBVPG $6757^{\mathrm{T}}[\mathrm{T}=$ type strain $]$ and DBVPG 6756 and Saccharomyces castellii DBVPG $6298^{\mathrm{T}}$ and DBVPG 6353) also produced one or occasionally two thick-walled ascospores (Fig. 1c through $f$ ). The spores of the type strain DBVPG 6757 of $P$. transvaalensis (Fig. 1c) were somewhat larger than those produced by Saccharomyces castelli and Saccharomyces dairensis, as noted previously by van der Walt and Liebenberg (16). In addition, the spores of $P$. transvaalensis DBVPG 6756 were also characterized by an outer surface covered with cilium-like appendages (Fig. 1d).

There has been much speculation concerning the relative merit of specific or generic separation based on differences in ascospore ultrastructure. Yamada and Banno (20) proposed that the genus Hasegawaea should be created for the species Schizosaccharomyces japonicus after Mikata and Banno (11) observed different spore surface structures in three of the four species of the genus Schizosaccharomyces sensu Yarrow (21). In contrast, Kreger-van Rij (6) was somewhat troubled to find that while the spores of most Zygosaccharomyces species had smooth outer walls, Zygosaccharomyces rouxii spores had warty surfaces quite similar to those observed in Debaryomyces hansenii (7). After evaluating ascospore ultrastructure, as well as a number of other characteristics, including coenzyme $Q$ systems, physiology, and ploidy, Kreger-van Rij (6) concluded that a different spore wall structure alone was not sufficient to separate species of the then-invalid genus Tonulaspora from the genus Saccharomyces. After a scanning electron microscope examination of spores of Debaryomyces and Saccharomyces strains, Kurtzman et al. (9) were also hesitant to make species or generic assignments solely on the basis of "the information obtained on ascospore surface-fine structure." 

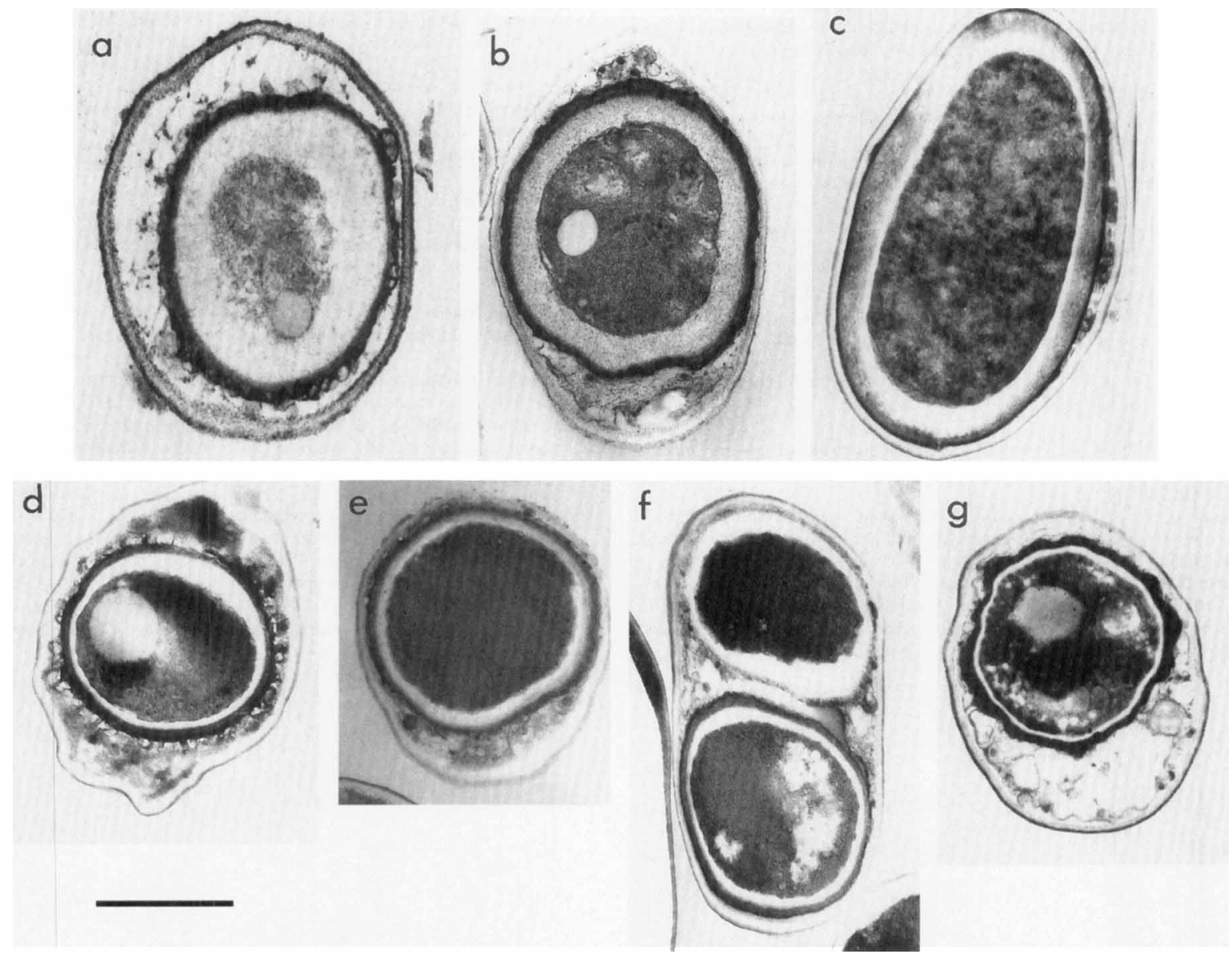

FIG. 1. Comparative ascospore morphology of Saccharomyces sensu lato strains. (a and b) S. dairensis DBVPG $6366^{\mathrm{T}}$; (c) Pachytichospora transvaalensis DBVPG $6757^{\mathrm{T}}$; (d) Pachytichospora transvaalensis DBVPG 6756; (e and f) $S$. castelli DBVPG $6298^{\mathrm{T}} ;(\mathrm{g}) S$. castelli DBVPG 6353. T indicates the type strain of the epithet. DBVPG, Industrial Yeasts Collection, Dipartmento di Biologia Vegetale, Università degli Studi, Perugia, Italy. Bar, $1 \mu \mathrm{m}$.

In light of the previously expressed opinions concerning the use of ascospore ultrastructure as a taxonomic tool and considering the observations made in this study, it appears that the monotypic genus Pachytichospora should be abolished and the species Saccharomyces transvaalensis van der Walt (14) should be reinstated. This conclusion is supported by the results of DNA-DNA reassociation studies which showed that Saccharomyces dairensis and Saccharomyces castellii can be clearly separated $(16 \mathrm{a}, 17,19)$ and that Pachytichospora transvaalensis DBVPG $6757^{\mathrm{T}}$ and DBVPG 6756 occupy an intermediate position between these two distinct taxa (16a).

Intermediate levels of DNA base sequence relatedness (ca. $60 \%$ ), such as those observed with Pachytichospora transvalensis DBVPG $6757^{\mathbf{T}}$ and DBVPG 6756 and the unrelated species Saccharomyces castellii and Saccharomyces dairensis (16a), can raise questions about the validity of continuing to recognize distinct taxa. Nevertheless, the maintenance of Saccharomyces transvaalensis as a separate Saccharomyces species is supported by the results of two other studies. van der Walt and Liebenberg (16) could not demonstrate that mating types of Saccharomyces transvaalensis and two strains classified as Saccharomyces dairensis, type strain DBVPG 6366 and strain CBS 1579 (= DBVPG 6410), were interfertile. The latter strain and DBVPG 6353 were shown to be more than 95\% homologous to the type strain of Saccharomyces castellii (19).
An analogous situation of greater-than-background DNA relatedness was also encountered within the sensu stricto group of the genus Saccharomyces. An extensive DNA-DNA reassociation study revealed that even though Saccharomyces pastorianus exhibits $52 \%$ homology with Saccharomyces cerevisiae and $72 \%$ homology with Saccharomyces bayanus, it must be maintained as a separate taxon since the latter two species exhibit less than $10 \%$ similarity in their nucleotide base sequences (18). This separation was confirmed by the results of a study (13) which revealed the probable hybrid nature of strains related to Saccharomyces pastorianus by showing that at least three double, homeologous chromosomes are present in this species. Classical genetic studies have also revealed that no fertile progeny are produced from spore-to-spore matings between Saccharomyces bayanus and Saccharomyces cerevisiae (1, 4). Similarly, Saccharomyces castellii, Saccharomyces dairensis, and Saccharomyces transvaalensis, which have been shown to exhibit low to intermediate levels of DNA base sequence relatedness $(16 \mathrm{a}, 17,19)$, to not be interfertile $(16)$, and to produce one or two thick-walled ascospores per ascus (this study), should be considered sibling and congeneric, but separate, species.

This research was supported by the National Research Council of Italy, Special project RAISA, Subproject 4, paper no. 2316. 


\section{REFERENCES}

1. Banno, I., and Y. Kaneko. 1989. A genetic analysis of taxonomic relation between Saccharomyces cerevisiae and Saccharomyces bayanus. Yeast 5:373377.

2. Black, S. H., and C. Gorman. 1971. The cytology of Hansenula. III. Nuclear segregation and envelopment during ascosporogenesis in Hansenula wingei. Arch. Mikrobiol. 79:231-248.

3. Capriotti, A. 1966. Saccharomyces castellii $n$. sp.: una nuova specie di lievito isolata da un terreno della Finlandia. Ann. Fac. Agrar. Sassari. 14:453-458.

4. Kishimoto, M. 1994. Fermentation characteristics of hybrids between the cryophilic wine yeast Saccharomyces bayanus and the mesophilic wine yeast Saccharomyces cerevisiae. J. Ferment. Bioeng. 77:432-435.

5. Kreger-van Rij, N. J. W. 1978. Electron microscopy of germinating ascospores of Saccharomyces cerevisiae. Arch. Microbiol. 117:73-77.

6. Kreger-van Rij, N. J. W. 1979. A comparative ultrastructural study of the ascospores of some Saccharomyces and Kluyveromyces species. Arch. Microbiol. 121:53-59.

7. Kreger-van Rij, N. J. W., and M. Veenhuis. 1975. Electron microscopy of ascus formation in the yeast Debaryomyces hansenii. J. Gen. Microbiol. 89: 256-264.

8. Kurtzman, C. P. 1984. Synonomy of the yeast genera Hansenula and Pichia demonstrated through comparison of deoxyribonucleic acid. Antonie Leeuwenhoek 50:209-217.

9. Kurtzman, C. P., M. J. Smiley, and F. L. Baker. 1975. Scanning electron microscopy of ascospores of Debaryomyces and Saccharomyces. Mycopathologia 55:29-34.

10. McClary, D. O., W. L. Nulty, and G. R. Miller. 1959. Effect of potassium versus sodium in the sporulation of Saccharomyces. J. Bacteriol 78:362-368.

11. Mikata, K., and I. Banno. 1987. Surface structure of ascospores of the genus Schizosaccharomyces. Inst. Ferment. Res. Commun. (Osaka) 13:45-51.
12. Naganishi, H. 1917. Three new species of yeasts. Bot. Mag. Tokyo 31:107-115. 13. Nilsson-Tillgren, T., C. Gjermansen, C. Holmberg, M. C. Holmberg, and J. G. L. Pedersen. 1981. Genetic differences between $S$. carlsbergensis and $S$ cerevisiae. Analysis of chromosome III by single chromosome transfers. Carlsberg Res. Commun. 46:64-76.

14. van der Walt, J. P. 1956. Saccharomyces transvaalensis nov. spec. A new yeast from soil. Antonie Leeuwenhoek 22:190-192.

15. van der Walt, J. P. 1978. The genus Pachytichospora gen. nov. Bothalia 12:563-564.

16. van der Walt, J. P., and N. V. D. W. Liebenberg. 1973. Agglutinative mating types of Saccharomyces transvaalensis. Antonie Leeuwenhoek 39:629-633.

16a.Vaughan-Martini, A., and S. Baraccia. 1996. A reconsideration of species related to Saccharomyces dairensis (Naganishi). Int. J. Syst. Bacteriol. 46: 313-317.

17. Vaughan-Martini, A., and C. P. Kurtzman. 1988. Deoxyribonucleic acid relatedness among species of Saccharomyces sensu lato. Mycologia 80:241243

18. Vaughan-Martini, A., and A. Martini. 1987. Three newly delimited species of Saccharomyces sensu stricto. Antonie Leeuwenhoek 53:77-84.

19. Vaughan-Martini, A., A. Martini, and G. Cardinali. 1993. Electrophoretic karyotyping as a taxonomic tool in the genus Saccharomyces. Antonie Leeuwenhoek 63:145-156.

20. Yamada, Y., and I. Banno. 1987. Hasegawaea gen. nov. An ascosporogenous yeast genus for the organisms whose asexual reproduction is by fission and whose ascospores have smooth surfaces without papillae and which are characterized by the absence of coenzyme $\mathrm{Q}$ and by the presence of linoleic acid in cellular fatty acid composition. J. Gen. Appl. Microbiol. 33:295-298.

21. Yarrow, D. 1984. Schizosaccharomyces Lindner, p. 414-422. In N. J. W. Kreger-van Rij (ed.), The yeasts: a taxonomic study, 3rd ed. Elsevier Science Publishers B.V., Amsterdam. 